\title{
Discrimination of artificial starry sky by pigeons
}

\section{Shigeru Watanabe ${ }^{1}$}

Published online: 10 February 2020

(C) The Psychonomic Society, Inc. 2020

\begin{abstract}
Night migratory birds use the star compass for their navigation. Here, I examined discrimination of a starry sky by a nonmigratory bird, the pigeon. Four pigeons were trained in an operant chamber to discriminate between an artificial starry sky created using software (Stella Theater Pro) and a black sky without stars. After they learned the task, they received three generalization tests. Test 1 presented a starry sky with different classes of stars (i.e., the number of stars was changed). Test 2 presented a starry sky at different times (i.e., a horizontal shift of the sky). Test 3 presented a starry sky at different latitudes (i.e., a vertical shift of the sky). The pigeons displayed a clear generalization gradient with a peak shift to the sky with more stars in Test 1 and a peak close to the original sky in Test 3, but almost a flat gradient in Test 2 . Therefore, pigeons demonstrated stimulus control using the pattern of the stars, and they were more sensitive to the vertical shift than to the horizontal shift.
\end{abstract}

Keywords Visual concept $\cdot$ Constellation $\cdot$ Visual discrimination $\cdot$ Pigeons

Humans have a highly developed visual system among mammals, as they can easily categorize patterns of complex visual stimuli. Constellations are one example of human visual pattern recognition; people see a scorpion, bear, crab, and so forth in a starry sky. Dry, Navarro, Preiss, and Lee (2009), who asked human observers to connect the points from star constellations, showed a consistency among the observers in their empirical perception of the constellations and reported that the obtained patterns were similar to the actual coordinates of the constellations. Köhler (1929) pointed out the Gestalt perception of a starry sky long ago. How do nonhuman species perceive the starry sky?

Migratory birds use several compasses- namely, sun compass, magnetic compass, star compass. The star compass is important for night-time migrating birds. Experimenting in a planetarium using an artificial sky, Sauer (1958) showed that flight direction of the lesser whitethroat (Sylvia curruca) was controlled by the position of the stars. Planetarium experiments with an artificial starry sky also revealed that the Indigo bunting (Passerina cyanea) takes off to the South in autumn (Emlen, 1967a, 1967b, 1969). Stellar orientations have since been reported in garden warblers (Sylvia borin;

Shigeru Watanabe swat@flet.keio.ac.jp

1 Department of Psychology, Keio University, 2-15-45 Mita, Minatoku, Tokyo, Japan
Wiltschko, Daum, Ferngenbauer-Kimmel, \& Wiltschko, 1987), savannah sparrows (Passerculus sandwichensis; Able \& Able, 1990), pied flycatchers (Ficedula hypoleuca), blackcaps (Sylvia atricapilla; Mouritsen \& Larsen, 2001), and European robins (Erithacus rubecula; Pakhomov, Anashina, $\&$ Chernetsov, 2017). These studies suggest that these birds can discriminate a starry sky. Such discriminative ability may have developed in these night-migratory species through phylogenetic contingency on migration. These night-time migratory birds develop a particular "night vision" system to detect the star pattern in the night sky. A cluster of neurons (Cluster $\mathrm{N}$ ) that is sensitive to visual stimulus in the dark environment is found in the hyperpallium of migrant birds (Zapka, Heyers, Liedvogel, Jarvis, \& Mouritsen, 2010).

The purpose of the present experiment is to examine discriminability of the starry sky in a nonmigrating bird, the pigeon. If pigeons can discriminate the starry sky, it will indicate that night-migratory birds use the general pattern recognition ability, not specific to the migrants, to solve their migratory problem. Pigeons have a sophisticated visual cognitive ability (see Watanabe, 2012; Watanabe \& Aust, 2016) that allows them to discriminate a triangle of dots, and the birds show a generalization gradient along the degree of distortion of the dot pattern (Watanabe, 1988).

In the present study, I employed software to create the pattern of a starry sky by determining time, position, and degree of brightness of the stars. Pigeons were trained to discriminate the patterns of stars and received tests displaying 
skies with different classes of stars, different times, and different latitudes to examine the discriminative stimulus property of constellations in pigeons.

\section{Method}

\section{Subjects}

Four experimentally naïve pigeons (Columba livia), obtained from the Japanese Racing Pigeon Association, were used. The pigeons lived in individual cages, and water was freely available. Room temperature was maintained at $24^{\circ} \mathrm{C}$. The birds maintained their body weight at $85 \%$ of their ad libitum weights. They were treated in accordance with the guidelines of the National Institutes of Health guide for the Care and Use of Laboratory Animals and the Animal Care and Use Committee of Keio University, and the guidelines of the Japanese Society for Animal Psychology.

\section{Apparatus}

The experimental chamber was a modified operant chamber for pigeons $(30 \times 25 \times 30 \mathrm{~cm}$, MED Associates Inc., VT05454, USA). The front panel had a rectangular transparent pecking key $(6 \times 6 \mathrm{~cm})$ through which subjects could see a computer screen (Power PCG4 iMax 2.1, $800 \mathrm{MHz}$ ). There was an electric liquid shutter (UM glass) between the key and the screen. The SKED system (MED Associates Inc.) controlled the experiment.

\section{Stimuli}

The starry sky was created using Stella Theater Pro (Toxsoft) that could create the sky at a particular time on a particular date and position. The class of stars can be also specified (Class 0 was the brightest and Class 9 the darkest). For example, the Class 5 sky was defined as a sky with stars brighter than Class 5 (i.e., stars of Classes 5, 4, 3, 2, and 1). The created sky was edited using PowerPoint. Figure 1 shows a sample of the stimuli. The starry sky used for discriminative training was a sky at 22:00 on January 19, 1948, from the position of latitude 25.633389 and longitude 139.732681, and stars less than Class 7 were displayed. This sky was the original sky. A dark sky without stars, a black rectangle prepared using PowerPoint, was also used for the discriminative training. Size of the sky was $6 \times 6 \mathrm{~cm}$.

Stimuli for Test 1 were the starry sky with stars above Classes 5, 6, 7, 8, and 9, and a dark-gray sky without stars (see Fig. 1): Class 5 contains Classes 1-5, Class 6 comprises Classes 1-6, and Class 9 includes Classes 1-9. That is, Class 5 is the darkest sky. It contains classes $1-5$. Class 9 conatins classes $1-9$, that is largest number of the stars. The darkgray sky was a gray rectangle prepared using PowerPoint and had illuminance similar to that of the original starry sky. An illuminometer (T-10MA; Konica Minolta Optics, Inc.) was used for this illuminance matching. The original starry sky at different times (18:00, 20:00, 22:00, and 24:00 of the same day and 02:00 of the next day) were used in Test 2 . The original starry sky at different latitudes - namely $6,21,36,51$, and $66^{\circ}$-was used in Test 3 . Illuminance of stimuli at the position of the pigeon was measured by the Illuminance meter. Results of the measurement are presented in Table 1.

\section{Procedure}

Pigeons were trained to peck the key using the auto-shaping procedure, and then trained on the Variable Interval $20 \mathrm{~s}$ (VI20 s) schedule. The discrimination task was to discriminate between an original starry sky and a dark sky without stars. Two stimuli were successively presented 20 times each according to the Gellerman series. One presentation was for $25 \mathrm{~s}$ followed by a 5-s blackout. The electric shutter was closed during the blackout period. Pecking response was reinforced on a VI25 s schedule when the starry sky appeared on the screen, while it was extinguished when the black sky appeared (mult VI25 sEXT schedule). The training continued until the discrimination ratio, obtained by dividing the number of responses to the starry sky by the total number of responses to the starry sky and black sky, was over 0.90 for two successive sessions.

Then, all subjects received three tests. Test 1 used the starry skies at the same time and date, but the class of the stars was above 5, 6, 7, 8, 9, a dark-gray sky, and the black sky. In Test 2 , the starry sky at different times $(18: 00,20: 00,22: 00$, and

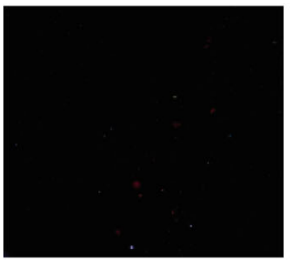

Class 5

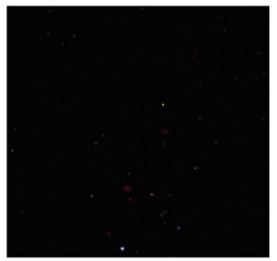

Class 6

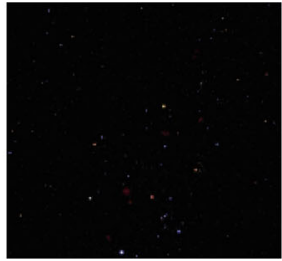

Class 7

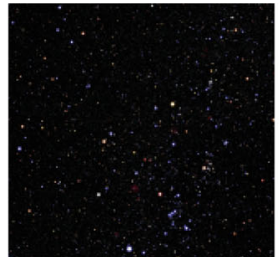

Class 8

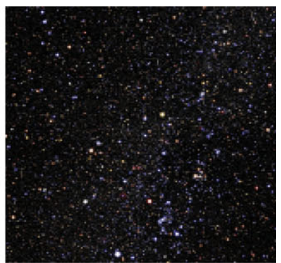

Class 9

Fig. 1 The starry skies with difference classes of stars used in Test 1 
Table 1 Illuminance of stimuli (Class 7 stimuli were used for the discriminative training. Illuminance is expressed in $\mathrm{ft}-\mathrm{L}$ )

\begin{tabular}{|c|c|c|c|c|c|c|c|}
\hline Test 1 & Class 9 & Cass 8 & Class 7 & Class 6 & Class 5 & Dark grey & Dark \\
\hline lluminance & 2.55 & 0.95 & 0.32 & 0.23 & 0.14 & 0.28 & 0.06 \\
\hline Test 2 & $8: 00$ & 20:00 & $22: 00$ & 24:00:00 & $2: 00$ & Dark grey & Dark \\
\hline lluminance & 0.14 & 0.27 & 0.32 & 0.3 & 0.27 & 0.28 & 0.06 \\
\hline Test 3 & Latitude 6 & Latitude 21 & Latitude 36 & Latitude 51 & Latitude 66 & Dark grey & Dark \\
\hline lluminance & 0.2 & 0.34 & 0.32 & 0.3 & 0.77 & 0.28 & 0.06 \\
\hline
\end{tabular}

24:00 of the same day and 02:00 of the next day) and the darkgray and black skies were presented. The 2-hour time difference gave a $16.4 \%$ shift in the horizontal axis. Change in time also resulted in a change in the brightness of the sky, but difference between 18:00 and 2:00 in Tokyo in January did not result in a big change in the illuminance (see Table 1 ). Test 3 used starry skies at different latitudes, namely $6,21,36,51$, and $66^{\circ}$ and the dark-gray and black skies. The latitude $21^{\circ}$ was closest to the original starry sky. Difference of $15^{\circ}$ gave a $12 \%$ shift in the vertical axis. In every test, the seven stimuli were presented seven times according to the Latin square design. One presentation was $25 \mathrm{~s}$ separated by a 5-s blackout period. Pecking responses to any stimuli were reinforced on VI25 s. The subjects received discriminative training between each test to maintain their discrimination. If the birds did not show a discrimination ratio above 0.90 , they were retrained until they reached the criterion of discrimination (two successive sessions with discrimination ratio above 0.90 ).

\section{Statistical analyses}

A one-way ANOVA was used to analyze stimulus control by starry sky. In the generalization tests, five starry skies and two skies without stars were presented, and responses to the five starry skies by four subjects were analyzed. After the ANOVA, I employed paired $t$ test for multiple comparisons with Holm's correction.

\section{Results}

The subjects reached the criterion in 18 to 25 sessions of the training. Figure 2 a presents the individual generalization gradients in Test 1 . The vertical axis indicates relative response to each stimulus (i.e., the number of responses to each stimulus was divided by the total number of responses to all stimuli in each bird and then the average of the four birds was calculated). The mean of the total number of pecks of the four subjects was 449.5 (170 to 604). The birds showed a generalization gradient along classes of the stars with a peak at Class 8 . Thus, they showed a peak shift toward more stars. Individually, two of the four birds showed a peak at Class 8 and the other two at Class 7 (the original sky). The dark-gray sky had illuminance similar to that of the original sky, but the birds emitted few responses to it; thus, the illuminance alone did not control the discriminative behavior. A one-way ANOVA showed a significant effect of class of stars, $F(4,19)=7.17, p=.002$, Power $=1.0$. A post hoc $t$ test showed significant difference between Classes 5 and $8, t(3)=3.95, p=.02$, difference $=$ 0.17 , confidence interval $=0.001$ to 0.19 ; between Classes 6 and $8, t(3)=5.35, p=.02$, difference $=0.29$, CI $[.0006, .20]$; and between Classes 8 and $9, t(3)=4.12, p=.04$, difference $=$ 0.15 , CI $[.001, .20]$. Thus, dimensional stimulus control along class of stars is clear.

Figure $2 \mathrm{~b}$ presents the results of Test 2 . The mean of the total number of pecks of the four subjects was 387.3 (219 to 588). No clear generalization gradient was observed. Two subjects showed a shallow peak at the original stimulus, one at the sky at 24:00, and the other did not show a clear peak. A one-way ANOVA did not show a significant effect of the time, $F(4,19)=1.23, p=.34$, Power $=0.87$. Therefore, the subjects were insensitive to the shift in the sky by time difference.

Results of Test 3 are presented in Fig. 2c. The mean of the total number of pecks to all test stimuli in the four subjects was 528.7 (180 to 878). Individually, three subjects showed a peak at $36^{\circ}$. A one-way ANOVA showed a significant effect of the latitude, $F(4,19)=4.61, p=.01$, Power $=0.99$. A post hoc $t$ test shows a significant difference between $6^{\circ}$ and $21^{\circ}, t(3)=$ $3.18, p=0.04$, difference $=0.03$, critical interval $=0.001$ to 0.10 , before Holm's correction, but the difference was not significant after the correction. Although all birds showed a peak at $51^{\circ}$, due to the variability of heights of the peak there was no statistically significant difference in responses between $51^{\circ}$ and other degrees.

\section{Discussion}

The present results clearly demonstrated discrimination of the artificial constellation in pigeons. The subjects did not emit responses to the dark-gray sky with illuminance similar to that of the original starry sky in all tests. Thus, they learned the discrimination not based on difference in illuminance. In Test 1 , the subjects showed a peak shift toward the sky with more stars. That is, the subjects responded more to the sky with more stars. Added stars increased illuminance of the sky, but 
a

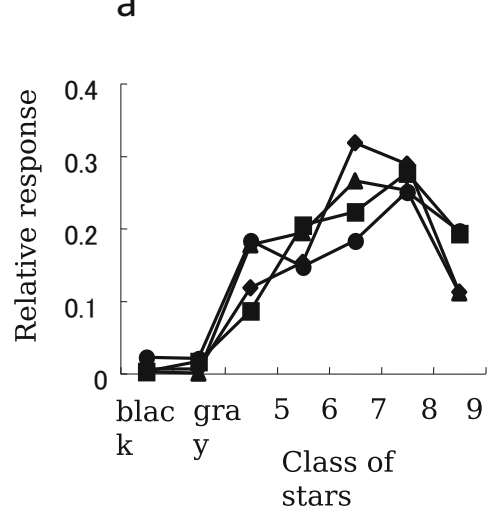

Fig. 2 Results of the generalization tests. a Test 1 shows generalization gradient along the dimension of the class of stars. Class 5 is the brightest class; thus, above Class 5, the sky has the least number of stars. Class 9 is the least bright class of stars; thus, above Class 9, the sky has the largest number of the stars. $\mathbf{b}$ Test 2 shows almost a flat gradient along the time of

might be a distraction to the detection of the pattern of the original sky. The subjects did not emit many responses to the brightest sky (Class 9), suggesting that the number of the original sky controlled the discrimination in pigeons.

Test 2 did not show a clear generalization gradient. Because the time difference in Test 2 means a horizontal shift of the sky on the screen, the results suggest that the pigeons were less sensitive to the horizontal shift of the sky. The time difference of 2 hours caused a shift of $16.4 \%$ of the sky on the screen. Thus, the 4-hour difference from the original sky means a $32.8 \%$ shift —in other words, around $67.2 \%$ of the sky was not changed. This remaining common area might control the pigeon's discriminative behavior. Because difference in illuminance among starry skies was $0.16 \mathrm{ft}-\mathrm{L}$ (the lightest $0.32 \mathrm{ft}$ $\mathrm{L}$ and the darkest $0.14 \mathrm{ft}-\mathrm{L}$ ), all starry skies had approximately similar illuminance.

Change of the latitude by $15^{\circ}$ caused a vertical shift of $12 \%$ of the sky on the screen, thus the maximum difference in the vertical axis was $24 \%$ from that of the original sky. In other words, the sky most shifted from the original sky still retained $76 \%$ common area with the original sky. Comparison with Test 2 suggests that the pigeons were sensitive more to the vertical shift (latitude) than to the horizontal shift (time difference) of the sky.

As described in the introduction, homing pigeons are not migratory birds, and they usually fly during the day and rest at night. Although the pigeons can fly under dim light, the starry sky is not their usual discriminative stimulus. Experimental data of constellation discrimination in pigeons is not available, but there are many migrant birds using the star map for their navigation (see Foster, Smolka, Nilsson \& Dacke, 2018, for a review). However, these experiments demonstrated preference for particular starry sky, not the discrimination between starry skies. The present experiment demonstrated the discrimination of the starry sky based on the pattern of the stars in pigeons. The
C

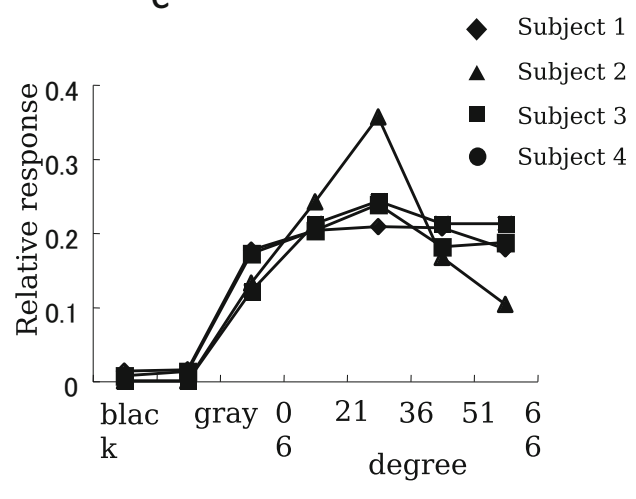

day. Difference in time means horizontal shift of the sky. $\mathbf{c}$ Test 3 shows generalization gradient along latitude. Difference in latitude means a vertical shift of the sky. The latitude of the original sky is $25^{\circ}$. All gradients are the mean of four birds

starry sky discrimination is not restricted to the night-migratory birds, and their ability of stellar mapping is based on general pattern discrimination ability shared with pigeons, not the nightmigratory bird. The present results do not demonstrate that every bird species has the ability for starry sky discrimination, but that this ability is not restricted to the nocturnal migrants.

Lea et al. (2018) used artificial stimuli differing in hue, orientation, and spatial frequency to train discrimination in pigeons and found that salience of the stimulus difference determined stimulus dimensions that controlled the discriminative behavior. The artificial constellation provides us seminatural stimulus comprising many different dimensions, and we can manipulate the stimuli to analyze visual cognition of such complex stimuli in the pigeon.

Acknowledgements The present research was supported by a Grant-inAid for Scientific Research by the Japanese Society for the Promotion of Science (18H01104).

Data availability statement Original data are available through swat@ flet.keio.ac.jp.

\section{References}

Able, P., \& Able, M. A. (1990). Calibration of the magnetic compass of a migratory bird by celestial rotation. Nature, 347, 378-380. doi: https://doi.org/10.1038/347378a0

Dry, M. J., Navarro, D. J., Preiss, K., \& Lee, M. D. (2009). The perceptual organization of point constellations. Proceedings of the 31st Annual Conference of the Cognitive Science Society (pp. 1151-1156). Retrieved from https://cognitivesciencesociety.org/wp-content/ uploads/2019/01/CogSci2009.pdf

Emlen, S. (1967a). Migratory orientation in the Indigo bunting, Passerina cyanea. Part I: Evidence for the use of celestial cues. The Auk, 84, 309-342. 
Emlen, S. (1967b). Migratory orientation in the Indigo bunting, Passerina cyanea. Part II: Mechanism of celestial orientation. The Auk, 84, 463-489.

Emlen, S. T. (1969). Bird migration: influence of physiological state upon celestial orientation. Science, 165, 716-718.

Foster, J. J., Smolka, J., Nilsson, D.-E., \& Dacke, M. (2018). How animals follow the stars. Proceeding of Royal Society, 285, 20172322. doi:https://doi.org/10.1098/rspb.2017.2322

Köhler, W. (1929). Gestalt psychology. New York, NY: Liveright.

Lea, S. G. E., Pothos, E. M., Wills, A. J., Leaver, L. A., Ryan, C. M. E., \& Meier, C. (2018). Multiple feature use in pigeons' category discrimination: The influence of stimulus set structure and the salience of stimulus differences. Journal of Experimental Psychology: Animal Learning and Cognition, 44, 114-127.

Mouritsen, H., \& Larsen, O. N. (2001). Migrating songbirds tested in computer-controlled Emlen funnels use stellar cues for a timeindependent compass. Journal of Experimental Biology, 204, $3855-3865$.

Pakhomov, A., Anashina, A., \& Chernetsov, N. (2017). Further evidence of a time-independent stellar compass in a night-migrating songbird. Behavioral Ecology \& Sociobiology, 71, 2-7. doi:https://doi.org/10. 1007/s00265-017-2279-3
Sauer, E. G. F. (1958). Celestial navigation by birds. Scientific American, 199, 42-47.

Watanabe, S. (1988). Failure of visual prototype learning in the pigeon. Animal Learning \& Behavior, 16, 147-152

Watanabe, S. (2012). "What" and "where" analysis and flexibility in avian visual cognition. In T. Zentall \& E. Wasserman (Eds.), The Oxford handbook of comparative cognition (pp. 757-775). Oxford, England: Oxford University Press.

Watanabe, S., \& Aust, U. (2016). Object and picture perception. In J. Call (Ed.), APA handbook of comparative psychology (pp. 117-140). Washington, DC: American Psychological Association.

Wiltschko, W., Daum, P., Ferngenbauer-Kimmel, A., \& Wiltschko, R. (1987). The development of the star compass in garden warblers, Sylvia borin. Ethology, 74, 285-292. doi:https://doi.org/10.1111/j. 1439-0310.1987.tb00939.x

Zapka, M., Heyers, D., Liedvogel, M., Jarvis, E., \& Mouritsen, H. (2010). Night-time neuronal activation of Cluster $\mathrm{N}$ in a day- and nightmigrating songbird. European Journal of Neuroscience, 32, 619624. doi:https://doi.org/10.1111/j.1460-9568.2010.07311

Publisher's note Springer Nature remains neutral with regard to jurisdictional claims in published maps and institutional affiliations. 